\title{
Ultrastructural alterations of the inferior alveolar nerve in wistar rats after alendronate administration per os: hypothesis for the generation of the "numb chin syndrome"
}

\author{
Eva-Maria Dietrich ${ }^{1 *}$, Papamitsou Theodora ${ }^{2}$, Sioga Antonia ${ }^{2}$, Koimtzis Georgios $^{2}$ and Neloum Esthelle ${ }^{2}$ \\ *Correspondence: aeffchen.dietrich@gmail.com

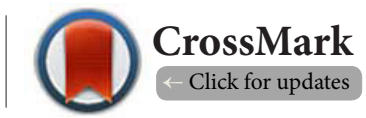 \\ 'Department of Oral and Maxillofacial Surgery, University Hospital of Erlangen, 91054 Erlangen, Germany. \\ 2Department of Histology and Embryology, Aristotle University of Thessaloniki, Medical School, 54174 Thessaloniki, Greece.
}

\begin{abstract}
Background: The neurological condition called 'numb chin syndrome', is a mental nerve neuropathy that is frequently associated with an underlying malignancy or infections. Bisphosphonate (BP) uptake has been recently identified as a new etiology for the syndrome. The mechanism that lies behind this neuropathy and the involvement of BPs have not been elucidated, yet. BPs can cause inhibition of endothelial cell proliferation, migration and adhesion, as well as impairment of capillary tubes formation. In humans, BPs result in reduction of vascularization in bone metabolic diseases, like Paget's disease. We hypothesize that BPs, taken per os, are capable of producing degenerative changes to the inferior alveolar nerve that may cause a mental nerve neuropathy.

Methods: In order to support our hypothesis we conducted an animal study, with Wistar rats, that was approved by the Bioethics Committee of our Institution. The animals were randomly allocated into two groups: Group A, the experimental group that consisted of 3 animals that were given Alendronate per os and Group B, the control group that also consisted of 3 animals, which were given normal saline. The duration was 13 weeks. The samples were observed under a Transmission Electron Microscope.

Results: Degenerative changes were defined as: vacuolization of the myelin sheath, detachment of the axon, local thickening and/or disruption of the myelin sheath. Local myelin thickening and detachment of the axon was found in both groups. Myelin sheath disruption was only seen in the control group whereas vacuolization of the myelin sheath was more profound in the experimental group. Interestingly, myelin sheath thickness was reduced in the experimental group.

Conclusions: Possible pathophysiological mechanisms causatively related to the histological alterations are: 1. alterations to the blood vessels of the nerve, 2. toxicity effects on Schwann and neuronal cells, or 3. changes to the innate or acquired immunity. The last may, probably, result from the presence of microbial films that cause cytokine production. The hypothesis provides scientific evidence for the presence of degenerative changes after BPs administration and helps in understanding of possible pathophysiological mechanisms.
\end{abstract}

Keywords: Alendronate, bisphosphonates, 'numb chin syndrome', inferior alveolar nerve (IAN)

\section{Introduction}

Bisphosphonate-related osteonecrosis of the jaws (BRONJ) is a category within the broader term of medication-related osteonecrosis of the jaws (MRONJ), a term that has been used in the report of the American Association of Oral and Maxillofacial Surgery (AAOMS) in 2014 [1]. It is defined by [2]:

1. A present or past history of BPs administration

2. The presence of bone exposure for more than 8 weeks

\section{The absence of a radiation history.}

It is accepted that MRONJ can occur without exposure of bone; such cases represent up to $1 / 3$ of the MRONJ [3].

The 'numb chin' is a neurological condition that affects the inferior alveolar nerve and the mental nerve and was reported for the first time by Charles Bell in 1829, as a manifestation of metastatic breast disease [4]. The term was used for the first time by Calverley and Mohnac in 1963 [5]. It describes a mental 
nerve neuropathy, with focal sensory loss and paresthesiaof the lower lip (mostly at one side) and the chin. In about 50\% of the cases a metastasis in the mandible is causatively related to the neuropathy. In adults, it mostly occurs in conjunction with breast cancer (64\%) and lymphomas (14\%) and in children with acute lymphoblastic leukemia [6].

Other etiologies are neurological disorders, trauma, diabetes, sickle cell anemia [7]. Mechanical pressure exerted on the nerve as well as other, yet unidentified mechanisms, seem to play an important role.

In cancer patients, the presence of a numb chin, is an in dicator of a poor prognosis because it is related to less than 1 year survival [8]. The mechanism for the generation of the numb chin syndrome in metastatic disease has not been identified, yet. Tumor infiltration is not a prerequisite for the syndrome [8]. Probably, it is a paraneoplastic phenomenon that accompanies cancer. However, no specific onconeural antibodies have been identified. Additionally, there is no scientific explanation for the occurrence of a mental nerve neuropathy mostly in breast cancer patients. It can be hypothesized that, a special mechanism that favors nerve-cell interactions is causatively related to the condition. This was shown for pancreatic carcinoma cells, in which a paracrine mechanism of cell-nerve communicationhas been recognized that involves TGF-alpha and EGFR interactionsand that could explain perineural spread in pancreatic adenocarcinomas [9]. However, this cannot explain the cases in which a mental nerve neuropathy exists without nerve infiltration. Neurogenesis has been recently reported to be important in breast cancerand could probably provide evidence of a possible neurophilic behaviour of breast cancer cells [10].

Numb chin syndrome related to BP use has been rarely reported in the literature and only in the form of case reports. The reason for the susceptibility of the IAN to BPs is still unclear. Whether the increased bone turnover in the mandibular bone, that is a plausible explanation for the susceptibility to BP-related osteonecrosis, is causatively related to IAN degeneration, or other factors, such as the mechanical stress exerted on the mandible during chewing, or alterations to the vessels of the mandibular neurovascular bundle or of those supplying the mandible $[11,12]$, that could probably alter the accumulation of BPs in the micro-environment of the nerve, or even inflammatory processes remains to be elucidated. Studies that involve the sciatic nerve in rats treated with BPs are conducted from our research group.

In the reported cases of "numb chin syndrome" there is mostly an osteolytic lesion in the mandible relatedto the neurological symptoms [13].The necessity of an osteolytic lesion for the generation of a mental nerve neuropathy was not elucidated, yet. It was not the aim of our investigation to show possible changes in the mandible after treatment with BPs. It would be interesting to investigate whether the presence of an osteolytic lesion is necessary for the generation of the neuropathy. If not, mental nerve neuropathy could be an early indicator of BRONJ, even before the generation of an osteolytic lesion on the Orthopantomogram. The present study aims to show possible ultrastructural changes of the IAN due to the administration of BPs that may support some of the theories raised regarding the pathophysiological mechanism.

\section{Background}

Bisphosphonates: classification of BRONJ, general issues BPs are drugs mainly implicated in the treatment of osteoporosis, metastatic disease with osteolytic bone metastases like in prostate or breast cancer, hypercalcemia and of hyperparathyroidism cases prior to parathyroidectomy $[\mathbf{1 4 , 1 5 ]}$.

The exact incidence of osteonecrosis of the jaws related to BP-therapy varies with regard to the underlying disease, the duration of treatment, the type of BP administered and the route of administration. Review articles reported on an incidence of BRONJ that ranged from 0 to $27.5 \%$ [3]. The discrepancy in the results is probably related to study design, the retrospective nature, the number of patients involved, the clinical and radiographic criteria and the general inclusion criteria.

There are two categories of BPs: early-generation BPs (like etidronate) that lack a nitrogen containing side chain and later-generation BPs (like alendronate and zoledronate) that are nitrogen-containing BPs. This difference influences their ability to inhibit bone resorption, because nitrogen-containing BPs inhibit bone resorption by 100 - to 10,000 -fold more than non-nitrogen containing ones [16].

The prominent classification of BRONJ proposed by AAOMS, was questioned by a retrospective European study in which the clinical findings proposed by the AAOMS were correlated to the radiographic findings on CT. Interestingly, about $57 \%$ of the patients classified as stage 0 had diffuse osteonecrosis and $1 / 3$ of patients with diffuse disease on CT were classified as stage 0 and 1 [17].

Mawardi et al., proposed changes to the current classification of BRONJ, in particular he suggested to include stage 0 category that would include the above cases, with clinical and radiological signs of BRONJ without bone exposure [18]. About $50 \%$ of the patients with stage 0 BRONJ will develop a stage 1,2 or 3 BRONJ [19].

Stage 1 disease refers to BRONJ cases with exposed bone or with bone that can be probed through a fistula and are asymptomatic with no signs of infection.

Stage 2 disease shows similar characteristics with stage 1 but the patients are symptomatic and have signs of infection.

Patients with stage 3 disease show apart from the characteristics of stage 2 one or more of the following [1]:

1. Exposed necrotic bone extending beyond the region of alveolar bone

2. Pathologic fracture

3. Extra-oral fistula

4. Oral-antral/oral-nasal communication

5. Osteolysis extending to the inferior border of the mandible or sinus floor. 
There are differences between different BP types regarding their capability of producing BRONJ. In particular, zoledronic acid is capable of producing BRONJ, on the contrary there is a lot of controversy regarding the incidence of alendronaterelated osteonecrosis of the jaws [20].

Per os administration seems not to be related to the same frequency to BRONJ with i.v. administration. In an animal tooth-extraction experiment in which the quantitative evaluation of the area of osteonecrosis of the specimens obtained after intraperitoneal administration of zoledronate was compared to the results of alendronate administration per os, it was shown that zoledronic acid caused osteonecrosis and microbial colonization whereas alendronate did not [20]. The explanation why alendronate when given per os is not related to the same frequency to osteonecrosis compared to intravenous administration of BPs, is that it only contains one nitrogen atom and it accumulates slower in bone. The number of nitrogen atoms is important for the binding of BPs to hydroxyapatite (HAP). Ebetino et al., have shown hydrogen binding between the nitrogen of the $\mathrm{R}_{2}$-side chain and $\mathrm{OH}$ on the HAP surface [21]. Thus, zoledronate that possesses 2 nitrogen atoms, accumulates faster in bone and this finding can also explain the shorter period that is takes for patients that receive i.v. zoledronate to show bone exposure $(9.4$ months), compared to those receiving alendronate per os (3 years ) [22]. Thus, the stereochemistry of the nitrogen chain and the number of nitrogen atoms play a crucial role for the susceptibility to BRONJ.

According to Merck, the manufacturer of alendronate, the incidence of BRONJ is $0.7 / 100,000$ person/years of exposure [23]. However, in contrary to what was believed previously, in particular that per os administration of BPs, like alendronate, is related to a lower risk of BRONJ, compared to i.v. administration of other BPs, newer investigations, have proven evidence of the fact that the frequency is considerable. In particular, in a retrospective study of Sedghizadeh et al., [1,24], $4 \%$ of the population that received alendronate per os ( $n: 208)$ showed BRONJ.

The explanation behind osteonecrosis and zoledronate administration probably lies in the loss of mucosal integrity that has been reported after i.v. administration [20]. This is the result of the inhibition of keratinocyte function and the impaired epithelialization in the region of the wound [25]. It remains to be elucidated whether:

1. The initial damage takes place in the mucosa or the adjacent bone.

2. The impairment of keratinocyte growth is the initializing factor for the loss of the protective action of the mucosa and osteonecrosis.

The skepticism behind the classification is that the correct categorization is important for the assessment of the severity of the disease according to which the appropriate therapy is chosen. The involvement of jaws and not long bones can be explained through the increased vascularity and bone turnover of the mandible and especially around the periodontium of the teeth. These result in high accumulation of BPs in the jaws [26].

\section{Bisphosphonates: possible ways of action}

Their main action is to inhibit bone resorption by interfering with the action of osteoclasts, which are involved in bone metabolism.

Two possible mechanisms of action have been described for BPs with regard to the inhibition of osteoclast action. Nitrogen-containing BPs inhibit the mevalonate pathway in osteoclasts, preventing prenylation of GTPase proteins necessary for osteoclast function.

On the contrary, BPs that lack nitrogen contribute to the formation of cytotoxic metabolites or inhibit tyrosine phosphatases in osteoclasts [27].

BPs inhibit osteoclast differentiation and induce osteoclast apoptosis [28]. This mechanism explains why BPs reduce skeletal morbidity by $30-50 \%$ in multiple myeloma patients and patients with solid tumors [29]. It's interesting to mention that BPs seem also to affect the disease-free survival of premenopausal women, receiving hormonal therapy for early stage breast cancer [30].

The fact that other antiresorptive drugs, such as denosumab, an anti-RANKL antibody that acts by inhibiting bone turnover, also cause osteonecrosis, supports the hypothesis that the main pathophysiological mechanism by which antiresorptive drugs cause osteonecrosis is inhibition of bone turnover, i.e. a dysregulation of the equilibrium between bone resorption and bone synthesis [31]. In particular, it has been shown that exactly because of this inhibition, denosumab results in a more profound compared to BPs reduction in the risk (about $17 \%$ ) of first skeletal-related event (SRE) as well as of the time until the first SRE (8.21 months) in metastatic disease [31].

The initial inhibition of osteoclasts, results in the end in dysregulated bone metabolism and reduced bone formation [32]. The first action makes these drugs inevitable for medical conditions characterized by dysregulated bone metabolism in favor of bone resorption, like osteoporosis or bone metastasis for example in case of breast or prostate cancer [33], and the second provides evidence for the discontinuation of these drugs after operations involving bone, as it was shown in a rabbit model ofintertransverse process arthrodesis [32].

Marx et al., characterized this dysregulation in bone remodeling as a chemical type of osteopetrosis, a genetic condition in which osteoclast function is inhibited [26].

New insides into the effects of BPs on the metabolism of other substances in the body, like lipoproteins promise to contribute to the elucidation of the complete spectrum of their action.

\section{Dose}

The doseof BP treatment in humans is $1 \mathrm{mg} / \mathrm{kg} /$ week. The choice for a $0.05 \mathrm{mg} / \mathrm{kg} /$ week dose in animals was mainly 
based on the pharmacokinetic behavior of the drug. In particular, it is known that there is no evidence that alendronate is metabolized in animals (it could be compared to the impaired elimination through the kidneys in patients with renal failure) [34]. In humans, alendronate has an oral bioavailability of $0.76 \%$ [35]. According to the above a dose adaptation in animals, in order to mimic the pharmacokinetics in humans and not to cause toxic side effects is necessary.

Additionally, the dose of $0.05 \mathrm{mg} / \mathrm{kg}$ used in our experiment has already been used in animal experiments with alendronate administration per os that aimed at investigating the effect of the administration on bone repair after spine-arthrodesis and autologous iliac crest transplant [32]. This dose can be compared to the therapeutic dose administered to humans. Of course, differences in drug metabolism, for example a faster clearance could cause differences in the results between animals and humans.

\section{Duration of administration}

The duration of administration was chosen according to the following facts:

1. Animal toxicology studies have shown that the administration of a drug for 1 month succeeds in detecting $90 \%$ of the toxic effects [36].

2. Fast accumulation of alendronate in bone tissue [28].

3. The same duration was chosen in other animal experiments with BPs [32].

The duration of administration plays a crucial role for the generation of osteonecrosis. In particular it has been advocated that alendronate administration for a maximum of 3 years does not increase the risk of osteonecrosis $[2,37]$.

\section{Nerve degeneration}

Some of the indicators of nerve degeneration are: demyelination, myelin disruption, axonal swelling, axoplasmic darkening and decrease in the number of axons (Table 1) [38]. Nerve tissue was shown to possess adaptive properties. In particular, degenerative changes of the IAN have been reported- to the best of our knowledge-up to now, only in animal models of distraction osteogenesis, a surgical process used to lengthen the long bones as well as the jaws. In these cases it was shown that a complete adaptation at distraction rates greater than $1 \mathrm{~mm} /$ day is not possible(animal model of distraction osteogenesis with gouts) [39].

Table 1. Histological findings of nerve degeneration [38].

Demyelination
Myelin disruption
Axonal swelling
Axoplasmicdarking
Decrease in the number of axons
Vacuolization of the myelin sheath
Detachment of the axon
Local thickening of the axon

Comparable results were reported in another animal model with dogs where a distraction rate of $1 \mathrm{~mm} /$ day in segmental defects in dogs, caused reversible degeneration at 3,6 and 12 months, through a phase of Wallerian degeneration [40]. Similar changes related to the administration of BPs and the generation of a numb chin have not been- to our knowledgereported in the literature, yet.

\section{Materials and methods \\ Animals}

The study was approved by the Bioethics Committee of the Medical School of the Aristotle University of Thessaloniki. Six female Wistar rats, 12-month old, weighing approximately 500 gr., were used in the experiment. Rats were housed in stainless steel cages, with one rat per cage, $12 \mathrm{~h}$ light-dark cycle, relative humidity and temperature control.

The animals were randomly allocated into two groups: Group A, the experimental group that consisted of 3 animals and Group B, the controlgroup that also consisted of 3 animals.

Alendronate (Fosamax, Merck) was administered per os to animals of Group A at a dose of $0.05 \mathrm{mg} / \mathrm{kg}$ body weight/ week dissolved in $3 \mathrm{cc}$ normal saline for 13 weeks. The drug was administered 30 at least minutes prior to breakfast once a week.

The dose calculation was according to the human dose that is normally administered. The duration of the study was limited to 13 weeks because of the fast accumulation of alendronate in bone tissue.

After euthanasia, the mandible of the animals was removed and the IAN wasexcised at its entrance in the mandibular canal, in animals of both groups and tissues were processed for electron microscopy.

We decided to use alendronate because $[\mathbf{2 8 , 4 1 ]}$ :

1. Of the growing evidence that oral administration of BP is more commonly related to BRONJ than actually believed

2. The fast accumulation of alendronate in bone.

Transmission Electron Microscopy (JEOL USA Transmission Electron Microscopes).

IAN tissue samples were sectioned into $<1 \mathrm{~cm}^{3}$ pieces. They were placed into glutaraldehyde $2.5 \%$ for 2 hours. Then into osmium tetroxide (OsO4) $1 \%$ for 1 hour. Staining was performed with uranyl acetate $1 \%$ (16 hours) and dehydration with advancing ethanol concentrations. Samples were embedded into Epon resin.

Ultra-thin sections (600-900 A) were taken and stained with Reynolds's stain. Samples were observed under a JEOL transmission electron microscope.

\section{Statistical analysis}

Five sections from each nerve were obtained. The micrographs were observed under a magnification of X4000. The parameter measured was the thickness of the myelin sheath. The Program Image J 1.48 (nih.gov) was used for the assessment of the thickness of the myelin sheath on two random, dia- 
metrically opposed locations on each neurofilament on each section. 250 neurofilaments were measured. The mean thickness was calculated. The observer was blinded to the group he was examining. The statistical analysis was conducted with a t-test (MS Excel).

\section{Results}

The ultrastructural analysis revealed that degenerative changes were present in both the experimental $(A)$ and the control group (B). Degenerative changes were defined as:

1. Vacuolization of the myelin sheath

2. Detachment of the axon

3. Local thickening and / or disruption of the myelin sheath. In particular, detachment of the axon was present in both the experimental Group (A) (Figure 1, red arrow)and the control Group (B) (Figure 2, red arrow), whereas disruption of the myelin sheath, by means of vacuolization inside the myelin was more profound in the experimental Group (A) (Figure 1, black arrows), compared to the control Group (Figure 2, black arrow).

Local thickening of the myelin sheath was observed in both groups (Figure 3a). Disruption of the myelin sheath was only observed in one neurofilament in one sample of the control Group (Figure $3 \mathbf{b}$ ). This could be the result of tissue processing.

The mean thickness of the myelin sheath between the two groups showed a statistically significant difference $(p<0.013)$ $(A=0,9391949 \mu \mathrm{m}$ vs. $B=1,1201515 \mu \mathrm{m})$. The analysis of the statistical error revealed the statistical significance of our results (Figure 4).

These results provide evidence that degenerative changes of the IAN take place irrespective of the administration of BPs. BPs administration to the experimental group resulted into a statistical significant reduction of the thickness of the myelin sheath $(p<0.05)$.

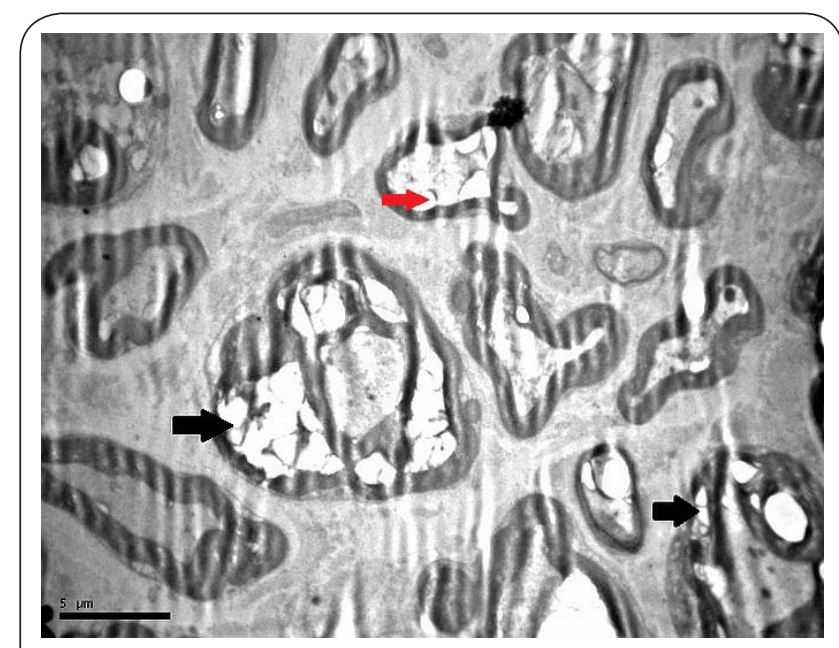

Figure 1. Experimental Group (A). The Figure shows profound disruption of the myelin sheath in the experimental group by means of intramyelin vacuolization (black arrows).Detachment of the axon and axoplasmic swelling is also present (red arrow).

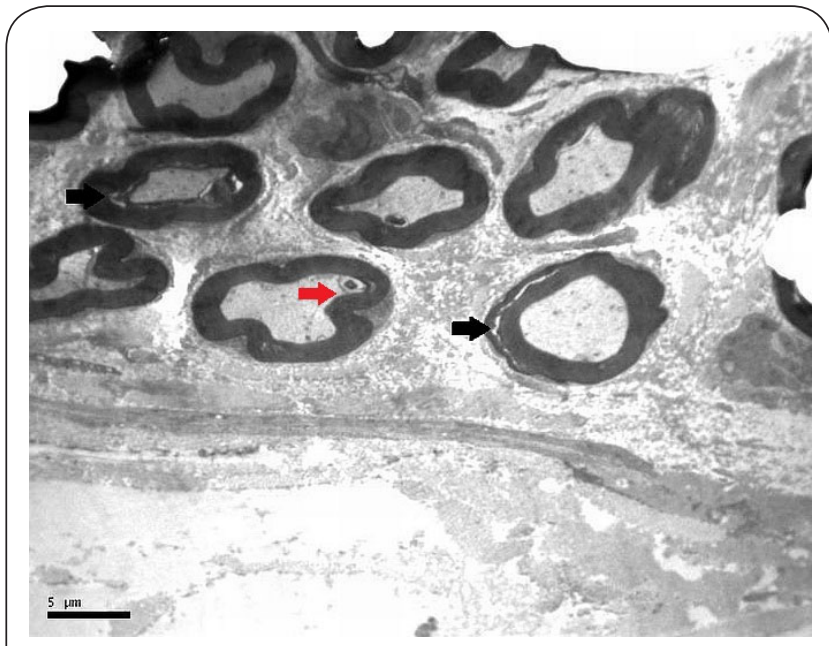

Figure 2. Control Group (B). The figure reveals detachment of the axon in one myelinated neurofilament (red arrow) and mild intramyelin vacuolization (black arrow).
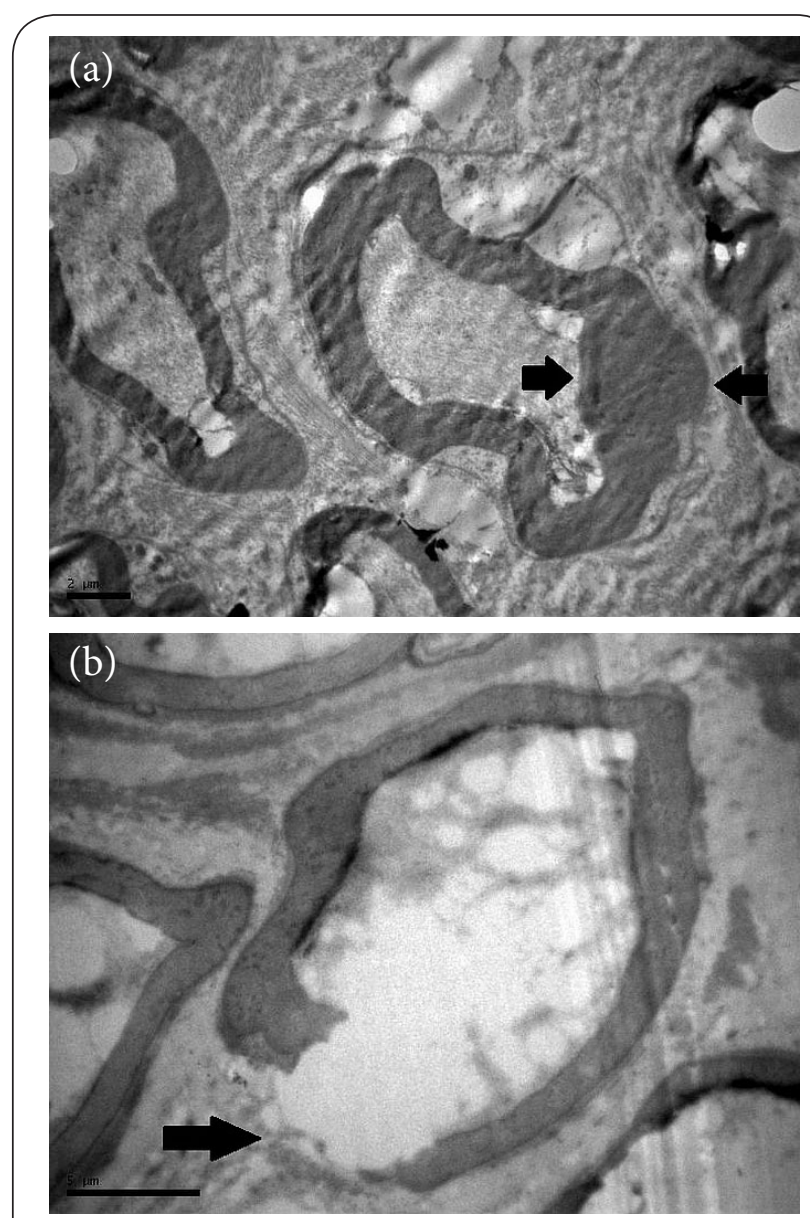

Figure 3. Control Group (B).

(a) Thickening of the myelin sheath (black arrows).

(b) The Figure shows disruption of the myelin sheath (black arrow). 


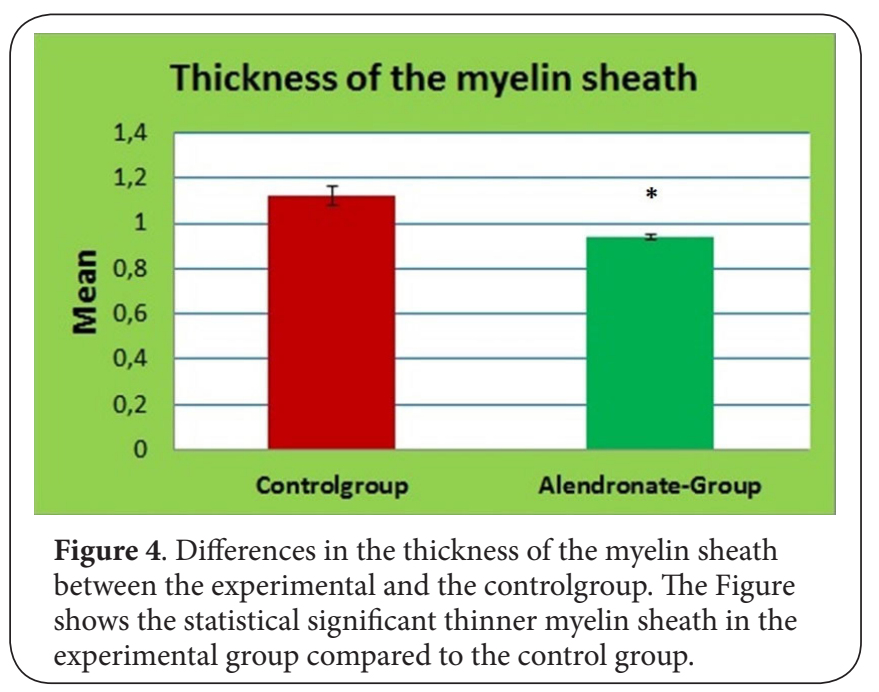

\section{Discussion \\ Mechanisms related to BRONJ that could cause a mental nerve neuropathy}

Our hypothesis is that the mechanism behind BP-related mental nerve neuropathy is related to ischemic alterations.

There are only a few published studies about the action of BP on vessels. In particular, an antiatherogenic action has been attributed to these drugs, because of the reduced Carotid Artery (CA) intima-media thickness (IMT) reported in postmenopausal osteoporotic women that received zoledronate, compared to women that did not receive BPs [41]. Anti-angiogenic properties of BP have been also proven in knock-out for LDL (-/-) mice, which were given angiotensin II in order to evaluate the frequency of Abdominal Aortic Aneurysms and the capability of BPs to prevent their generation [42]. The experiments have shown that mice receiving i.v. zoledronate, show a significant reduction of the frequency of aneurysms and vascular inflammation. Additionally, it has been shown that in vitro zoledronate administration, resulted in inhibition of human umbilical endothelial cell and rat aortic ring cell proliferation, as well as into modulation of endothelial cell adhesion and migration [43] and impairment of capillary tube formation [44]. A reduction of vascularization has been reported in bone biopsy samples in patients with Paget's disease after initiation of BP treatment. The authors stress that it cannot be excluded that this finding may be the result of the reduction of bone resorption [44].

Other investigators, tried to elucidate the influence of BPs on vascular metabolism by investigating the immunohistochemical changes, like of VEGF production (the most important proangiogenic factor). These investigations did not show significant changes in VEGF staining in the mandible at the tooth extraction site in rats receiving BP [20]. On the contrary, differences have been found in the serum of patients after receiving zoledronate i.v.. In particular, a reduction of serum VEGF was found in cancer patients under BP therapy. The concentration gradually decreased about $34 \%$ at day 21 [45]. According to the above, an involvement of BPs in endothelial cell metabolism cannot be excluded. Despite this interference with vascular metabolism, a definite action on vascular cells has not been reported, yet.

Cell Toxicity is another possible explanation for the effects of BPs on nerve tissue. In particular, pamidronate administration resulted into reduction of the proliferation of murine keratinocytes without any alterations in cell apoptosis. Wound healing was also reduced in this animal study [46]. A dysregulation of the innate or acquired immunity has also been suggested for the generation of BRONJ. The elucidation of this mechanism in the generation of osteonecrosis still remains unclear, because there are only a few publications that address this issue. In an animal BRONJ model with mice that were administered zoledronate and dexamethasone, a suppression of T-regulatory cells and an activation of T-helper cells producing IL-17 was reported [47]. Systemic administration of mesenchymal stem cells (MSCs) was shown to reduce IL-17-producing T-cells and to increase the number of T-regulator cells. Thus, cells of the innate or acquired immunity and the expressed cytokines, may be related to IAN alterations.

The explanation for the vacuolization of the myelin sheath after alendronate administration is still hypothetical. We hypothesize that ischemic alterations to the Schwann cells may result into the observed degenerations. Similar alterations, for example vacuolization of Schwann cells (and mostly of satellite cells) were observed in the spinal ganglia of dogs after aortic occlusion, a finding that provides evidence of the fact that ischemic alterations to Schwann cells can cause cytoplasmic vacuolization [48]. The presence of vacuoles in the myelin is not able to explain the clinical picture. Other experimental studies that presented ultrastructural alterations by means of intramyelin vacuolization, did not reveal any changes in nerve electrophysiology. Thus, histological alterations do not always result into a particular clinical picture [49].

Direct effects on the neuron, for example by means of metabolic or toxic changes, like those presented formurine keratinocytes and resulted into inhibition of in vitro proliferation could not be excluded, however, due to the fact that Schwann cells are directly related to myelin synthesis we hypothesize that alterations to Schwann cells are causatively related to the generation of mental nerve neuropathy in patients receiving BPs [46].

\section{Conclusions}

Our study provides evidence for the first time-to our knowledge- that BP treatment may cause ultrastructural alterations of the inferior alveolar nerve. These changes are characterized by reduction in the thickness of the myelin sheath compared to the control group and by profound vacuolization into the myelin sheath.

Characteristics of our study that could have influenced our results are:

1. The duration of administration, that was 13 weeks. 
2. Dosing. Probably a higher dose may have caused more severe results.

3. The fact that our study was performed on animals.

4. The route of administration, i.e., per os, could have influenced our results.

Aspects that were not addressed are:

1. The presence or absence of an osteolytic lesion in the alveolar process or in the mandibular bone, in order to diagnose a BRONJ was not investigated. Whether the preexistence of an osteolysis is necessary for the genera tion of the neuropathy, or if the symptoms occur even in the absence of radiographic signs, is still unclear.

2. No conclusions regarding the function of the IAN were drawn. Neurophysiological assessment would be of great interest for further research.

3. Only morphological changes were addressed.

Future investigations that will address similar nerve degenerative changes in other nerves like the sciatic nerve in animal studies, as well as histological investigations in human cadavers and human studies that will investigate the correlation between histological and clinical findings in conjunction with age-related studies, will shed light upon the pathophysiologic mechanism of nerve degeneration under BP therapy, the exact involvement of BPs, the reversibility of the changes after discontinuation of BP uptake and the possibility of the co-administration of neuroprotective drugs.

\section{List of abbreviations}

AAOMS: American Association of Oral and Maxillofacial Surgery BP: Bisphosphonates

BRONJ: Bisphosphonate-Related Osteonecrosis of the Jaws IAN: Inferior Alveolar Nerve

\section{Competing interests}

The authors declare that they have no competing interests.

Authors' contributions

\begin{tabular}{|l|c|c|c|c|c|}
\hline Authors' contributions & DE & PT & SA & KG & NE \\
\hline Research concept and design & $\checkmark$ & $\checkmark$ & $\checkmark$ & -- & -- \\
\hline Collection and/or assembly of data & $\checkmark$ & $\checkmark$ & $\checkmark$ & $\checkmark$ & $\checkmark$ \\
\hline Data analysis and interpretation & $\checkmark$ & $\checkmark$ & $\checkmark$ & -- & -- \\
\hline Writing the article & $\checkmark$ & $\checkmark$ & $\checkmark$ & $\checkmark$ & $\checkmark$ \\
\hline Critical revision of the article & $\checkmark$ & -- & -- & -- & -- \\
\hline Final approval of article & $\checkmark$ & $\checkmark$ & $\checkmark$ & $\checkmark$ & $\checkmark$ \\
\hline Statistical analysis & $\checkmark$ & -- & -- & $\checkmark$ & $\checkmark$ \\
\hline
\end{tabular}

\section{Publication history}

Editor: Lingyan Wang, Oregon Health \& Science University, Portland. EIC: Gaetano Giuseppe Magro, University of Catania, Italy. Received: 03-Nov-2015 Final Revised: 02-Dec-2015 Accepted: 16-Dec-2015 Published: 24-Dec-2015

\section{References}

1. Colella G, Campisi G and Fusco V. American Association of Oral and Maxillofacial Surgeons position paper: Bisphosphonate-Related Osteonecrosis of the Jaws-2009 update: the need to refine the BRONJ definition. J Oral Maxillofac Surg. 2009; 67:2698-9. | Article | PubMed
2. American Association of Oral and Maxillofacial Surgeons position paper on bisphosphonate-related osteonecrosis of the jaws. J Oral Maxillofac Surg. 2007; 65:369-76. | Article | PubMed

3. Kuhl S, Walter C, Acham S, Pfeffer R and Lambrecht JT. Bisphosphonaterelated osteonecrosis of the jaws--a review. Oral Oncol. 2012; 48:93847. | Article | PubMed

4. Furukawa T. Charles Bell's description of numb chin syndrome. Neurology. 1988; 38:331. I Article

5. Calverley JR and Mohnac AM. Syndrome of the Numb Chin. Arch Intern Med. 1963; 112:819-21. | Article I PubMed

6. Lossos A and Siegal T. Numb chin syndrome in cancer patients: etiology, response to treatment, and prognostic significance. Neurology. 1992; 42:1181-4. | Article | PubMed

7. Turner-lannacci A, Mozaffari E and Stoopler ET. Mental nerve neuropathy: case report and review. CJEM. 2003; 5:259-62. I PubMed

8. Laurencet FM, Anchisi S, Tullen E and Dietrich PY. Mental neuropathy: report of five cases and review of the literature. Crit Rev Oncol Hematol. 2000; 34:71-9. | Article | PubMed

9. Bockman DE, Buchler M and Beger HG. Interaction of pancreatic ductal carcinoma with nerves leads to nerve damage. Gastroenterology. 1994; 107:219-30. | Article | PubMed

10. Zhao Q, Yang Y, Liang X, Du G, Liu L, Lu L, Dong J, Han H and Zhang G. The clinicopathological significance of neurogenesis in breast cancer. $B M C$ Cancer. 2014; 14:484. | Article I PubMed Abstract | PubMed Full Text

11. Wadu SG, Penhall B and Townsend GC. Morphological variability of the human inferior alveolar nerve. Clin Anat. 1997; 10:82-7. | Article | PubMed

12. Dietrich EM and Antoniades K. Physiological and pathological changes in the arterial supply of the mandible. Literature review. Hell Arch Oral Maxillofac Surg. 2012; 3:131-43. I Pdf

13. Sierra-Hidalgo F, de Pablo-Fernandez E, Correas-Callero E and VillarejoGalende A. [Numb chin syndrome caused by biphosphonates-induced osteonecrosis of the jaw]. Rev Neurol. 2009; 49:190-2. | Article | PubMed

14. Singh DN, Gupta SK, Kumari N, Krishnani N, Chand G, Mishra A, Agarwal G, Verma AK, Mishra SK and Agarwal A. Primary hyperparathyroidism presenting as hypercalcemic crisis: Twenty-year experience. Indian J Endocrinol Metab. 2015; 19:100-5. | Article | PubMed Abstract | PubMed Full Text

15. Phitayakorn R and McHenry CR. Hyperparathyroid crisis: use of bisphosphonates as a bridge to parathyroidectomy. J Am Coll Surg. 2008; 206:1106-15. | Article | PubMed

16. Kennel KA and Drake MT. Adverse effects of bisphosphonates: implications for osteoporosis management. Mayo Clin Proc. 2009; 84:632-7. | Article | PubMed Abstract | PubMed Full Text

17. Bedogni A, Fedele S, Bedogni G, Scoletta M, Favia G, Colella G, Agrillo A, Bettini G, Di Fede O, Oteri G, Fusco V, Gabriele M, Ottolenghi L, Valsecchi S, Porter S, Petruzzi M, Arduino P, D’Amato S, Ungari C, Fung Polly PL, Saia $G$ and Campisi G. Staging of osteonecrosis of the jaw requires computed tomography for accurate definition of the extent of bony disease. $\mathrm{Br} J$ Oral Maxillofac Surg. 2014; 52:603-8. | Article | PubMed

18. Mawardi H, Treister N, Richardson P, Anderson K, Munshi N, Faiella RA and Woo SB. Sinus tracts--an early sign of bisphosphonate-associated osteonecrosis of the jaws? J Oral Maxillofac Surg. 2009; 67:593-601. I Article I PubMed

19. Fedele S, Porter SR, D'Aiuto F, Aljohani S, Vescovi P, Manfredi M, Arduino PG, Broccoletti R, Musciotto A, Di Fede O, Lazarovici TS, Campisi G and Yarom N. Nonexposed variant of bisphosphonate-associated osteonecrosis of the jaw: a case series. Am J Med. 2010; 123:1060-4. | Article I PubMed

20. Maahs MP, Azambuja AA, Campos MM, Salum FG and Cherubini K. Association between bisphosphonates and jaw osteonecrosis: a study in Wistar rats. Head Neck. 2011; 33:199-207. I Article I PubMed

21. Ebetino FH, Barnett BL and Russell RGG. A computational model delineates differences in hydroxyapatite binding affinities of important bisphosphonates in clinical use. J Bone Miner Res. 2005; 20:259. | Pdf 
Dietrich et al. Journal of Histology \& Histopathology 2015,

22. Hu J, Tang Z, Wang D and Buckley MJ. Changes in the inferior alveolar nerve after mandibular lengthening with different rates of distraction. $J$ Oral Maxillofac Surg. 2001; 59:1041-5. I Article | PubMed

23. Edwards BJ, Hellstein JW, Jacobsen PL, Kaltman S, Mariotti A and Migliorati CA. Report of the Council of Scientific Affairs. Expert panel recommendations: dental management of patients on oral bisphosphonate therapy. JADA. 2006; 137:114450.

24. Sedghizadeh PP, Stanley K, Caligiuri M, Hofkes S, Lowry B and Shuler CF. Oral bisphosphonate use and the prevalence of osteonecrosis of the jaw: an institutional inquiry. J Am Dent Assoc. 2009; 140:61-6. I Article | PubMed

25. Close B, Banister K, Baumans V, Bernoth EM, Bromage N, Bunyan J, Erhardt W, Flecknell P, Gregory N, Hackbarth H, Morton D and Warwick C. Recommendations for euthanasia of experimental animals: Part 2. DGXT of the European Commission. Lab Anim. 1997; 31:1-32. | Pdf | PubMed

26. Marx RE. Pamidronate (Aredia) and zoledronate (Zometa) induced avascular necrosis of the jaws: a growing epidemic. J Oral Maxillofac Surg. 2003; 61:1115-7. I Article I PubMed

27. Rogers MJ, Gordon S, Benford HL, Coxon FP, Luckman SP, Monkkonen $\mathrm{J}$ and Frith JC. Cellular and molecular mechanisms of action of bisphosphonates. Cancer. 2000; 88:2961-78. | Article | PubMed

28. Sato M, Grasser W, Endo N, Akins R, Simmons H, Thompson DD, Golub $E$ and Rodan GA. Bisphosphonate action. Alendronate localization in rat bone and effects on osteoclast ultrastructure. J Clin Invest. 1991; 88:2095-105. | Article | PubMed Abstract | PubMed Full Text

29. Coleman RE and McCloskey EV. Bisphosphonates in oncology. Bone. 2011; 49:71-6. | Article | PubMed

30. Gnant M, Mlineritsch B, Stoeger $H$, Luschin-Ebengreuth $G$, Heck D, Menzel C, Jakesz R, Seifert M, Hubalek M, Pristauz G, Bauernhofer T, Eidtmann H, Eiermann W, Steger G, Kwasny W, Dubsky P, Hochreiner $\mathrm{G}$, Forsthuber EP, FesI C and Greil R. Adjuvant endocrine therapy plus zoledronic acid in premenopausal women with early-stage breast cancer: 62-month follow-up from the ABCSG-12 randomised trial. Lancet Oncol. 2011; 12:631-41. | Article | PubMed

31. Lipton A, Fizazi K, Stopeck AT, Henry DH, Brown JE, Yardley DA, Richardson GE, Siena S, Maroto P, Clemens M, Bilynskyy B, Charu V, Beuzeboc P, Rader M, Viniegra M, Saad F, Ke C, Braun A and Jun S. Superiority of denosumab to zoledronic acid for prevention of skeletalrelated events: a combined analysis of 3 pivotal, randomised, phase 3 trials. Eur J Cancer. 2012; 48:3082-92. I Article I PubMed

32. Lehman RA, Jr., Kuklo TR, Freedman BA, Cowart JR, Mense MG and Riew $K D$. The effect of alendronate sodium on spinal fusion: a rabbit model. Spine J. 2004; 4:36-43. | Article | PubMed

33. Vasikaran SD. Bisphosphonates: an overview with special reference to alendronate. Ann Clin Biochem. 2001; 38:608-23. | Article I PubMed

34. FOSAMAX Tablets. Drug information. Merck Sharp \& Dohme Corp. 2015. I Website

35. Gertz BJ, Holland SD, Kline WF, Matuszewski BK, Freeman A, Quan $\mathrm{H}$, Lasseter KC, Mucklow JC and Porras AG. Oral bioavailability and dose proportionality of alendronate (aminohydroxylbutylidene bisphosphonate) in postmenopausal women. J Bone Miner Res. 1991; 6:281.

36. Greaves $P$, Williams $A$ and Eve $M$. First dose of potential new medicines to humans: how animals help. Nat Rev Drug Discov. 2004; 3:226-36. Article I PubMed

37. Marx RE, Sawatari Y, Fortin M and Broumand V. Bisphosphonate-induced exposed bone (osteonecrosis/osteopetrosis) of the jaws: risk factors, recognition, prevention, and treatment. J Oral Maxillofac Surg. 2005; 63:1567-75. | Article | PubMed

38. Hu J, Tang Z, Wang D and Buckley MJ. Changes in the inferior alveolar nerve after mandibular lengthening with different rates of distraction. $J$ Oral Maxillofac Surg. 2001; 59:1041-5. | Article | PubMed

39. Skoulis TG, Vekris MD and Terzis JK. Effect of distraction osteogenesis on the peripheral nerve: experimental study in the rat. J Reconstr Microsurg. 1998; 14:565-74. | Article | PubMed
40. Isomura ET, Shogen Y, Hamaguchi M, Harada T, Tanaka N and Kogo M.Inferior alveolar nerve regeneration after bifocal distraction osteogenesis in dogs. Plast Reconstr Surg. 2013; 132:877-82. | Article

41. Gonnelli S, Caffarelli C, Tanzilli L, Pondrelli C, Lucani B, Franci BM and Nuti R. Effects of intravenous zoledronate and ibandronate on carotid intima-media thickness, lipids and FGF-23 in postmenopausal osteoporotic women. Bone. 2014; 61:27-32. | Article | PubMed

42. Tsai SH, Huang PH, Peng YJ, Chang WC, Tsai HY, Leu HB, Chen JW and Lin SJ. Zoledronate attenuates angiotensin II-induced abdominal aortic aneurysm through inactivation of Rho/ROCK-dependent JNK and NFkappaB pathway. Cardiovasc Res. 2013; 100:501-10. | Article | PubMed

43. Wood J, Bonjean K, Ruetz S, Bellahcene A, Devy L, Foidart JM, Castronovo $V$ and Green JR. Novel antiangiogenic effects of the bisphosphonate compound zoledronic acid. J Pharmacol Exp Ther. 2002; 302:1055-61. I Article | PubMed

44. Fournier P, Boissier S, Filleur S, Guglielmi J, Cabon F, Colombel M and Clezardin P. Bisphosphonates inhibit angiogenesis in vitro and testosterone-stimulated vascular regrowth in the ventral prostate in castrated rats. Cancer Res. 2002; 62:6538-44. I Article I PubMed

45. Santini D, Vincenzi B, Dicuonzo G, Avvisati G, Massacesi C, Battistoni F, Gavasci M, Rocci L, Tirindelli MC, Altomare V, Tocchini M, Bonsignori $\mathrm{M}$ and Tonini $\mathrm{G}$. Zoledronic acid induces significant and long-lasting modifications of circulating angiogenic factors in cancer patients. Clin Cancer Res. 2003; 9:2893-7. I Article | PubMed

46. Landesberg R, Cozin M, Cremers S, Woo V, Kousteni S, Sinha S, GarrettSinha $L$ and Raghavan $S$. Inhibition of oral mucosal cell wound healing by bisphosphonates. J Oral Maxillofac Surg. 2008; 66:839-47. | Article | PubMed Abstract I PubMed Full Text

47. Kikuiri T, Kim I, Yamaza T, Akiyama K, Zhang Q, Li Y, Chen C, Chen W, Wang $S$, Le AD and Shi S. Cell-based immunotherapy with mesenchymal stem cells cures bisphosphonate-related osteonecrosis of the jaw-like disease in mice. J Bone Miner Res. 2010; 25:1668-79. | Article | PubMed Abstract I PubMed Full Text

48. Fercakova A, Orendacova J, Marsala J and Marossy A. Changes in spinal ganglia satellite and Schwann cells after aortic occlusion. J Hirnforsch. 1983; 24:627-32. | Article | PubMed

49. Daglioglu E, Berker M, Demirci M, Tuncel M, Karabulut E and Tuncel A Microscopic and electrophysiological changes on regenerating sciatic nerves of rats treated with simvastatin. Folia Neuropathol. 2010; 48:4956. | Article | PubMed

\section{Citation:}

Dietrich E-M, Theodora P, Antonia S, Georgios $\mathrm{K}$ and Esthelle $\mathrm{N}$. Ultrastructural alterations of the inferior alveolar nerve in wistar rats after alendronate administration per os: hypothesis for the generation of the "numb chin syndrome".

J Histol Histopathol. 2015; 2:24.

http://dx.doi.org/10.7243/2055-091X-2-24 